\title{
CONHECIMENTO NECESSÁRIO PARA FUGIR DO JUROS NEGATIVOS
}

\author{
Alexandre Godinho Bertoncello, Felipe Natan dos Anjos \\ Universidade do Oeste Paulista - UNOESTE, Presidente Prudente, SP. E-mail: bertoncello@unoeste.br
}

\section{RESUMO}

Os juros no Brasil foram historicamente altos e por este motivo a forma de investimento no país sempre foi pouco sofisticada, grandes investidores faziam rendas fixas, como o CDI e pequenos investidores aplicavam na poupança. No presente cenário nacional 2019 / 2020 é possível observar que o Brasil terá condições macroeconômicas muito diferentes das vividas nos últimos anos, passando a ter diminuição da oferta agregada governamental, redução do aumento da dívida pública e das famílias, e uma grande redução nas taxas de juros. Nos próximos anos será importante diversificar os investimentos, afinal o fenômeno de juros negativos presente em outros mercados será uma realidade nacional. Para obter respostas foram utilizadas abordagens quantitativas e exploratórias, e posteriormente o método comparativo, para corroborar na correlação entre acúmulo de capital e o cenário macroeconômico. Como resultado foi possível averiguar que não há correlação entre taxa base de juros e endividamento e sim, uma relação de rentabilidade de investimentos tradicionais e os juros, ao mesmo tempo, níveis educacionais tem relação direta com o endividamento e assim conclui-se que existe uma nova realidade monetária, mas ainda não temos uma nova realidade de investidores e tomadores de crédito no Brasil.

Palavras-chave: Endividamento; Educação Financeira; Administração.

\section{KNOWLEDGE NEEDED TO ESCAPE NEGATIVE INTEREST}

\begin{abstract}
Interest rates in Brazil have historically been high and for this reason the form of investment in the country has always been unsophisticated, large investors made fixed income, as the CDI and small investors applied in savings. In the present national scenario 2019/2020, it is possible to observe that Brazil will have macroeconomic conditions very different from those experienced in recent years, with a decrease in the aggregate government supply, a reduction in the increase in public and household debt, and a great reduction in interest rates. interest. In the coming years it will be important to diversify investments, after all the phenomenon of negative interest in other markets will be a national reality. To obtain answers, quantitative and exploratory approaches were used, and later the comparative method, to corroborate the correlation between capital accumulation and the macroeconomic scenario. As a result, it was possible to ascertain that there is no correlation between the base interest rate and indebtedness, but that there is a relationship between the return on traditional investments and interest, at the same time, educational levels have a direct relationship with indebtedness and thus we conclude that there is a new monetary reality, but we still do not have a new reality for investors and borrowers in Brazil.
\end{abstract}

Keywords: Indebtedness; Financial Education; Administration.

\section{INTRODUÇÃO}

A educação financeira é uma forma de estimular as pessoas a iniciarem um processo constante de busca por aprendizagem, tomadas de decisões, e alcançar o acúmulo de capital financeiro, provenientes de trade off assertivos 
que como consequência trará benefícios aos envolvidos.

Para Olivieri (2013), o processo de educação financeira deviria começar dês da infância por volta dos 2 anos de idade, quando a criança começa a fazer seus primeiros pedidos de dinheiro, para doces e brinquedos. É aí que a educação começa ser de fundamental importância, para conscientização, conhecimento e aprendizado de novas regras, equilíbrio e valores para se utilizar o dinheiro. Porém convém que este procedimento seja acompanhado pelos pais, para que ela aprenda controlar seus impulsos e limites dês de cedo.

Lembra-se que a educação financeira não é somente importante para Jovens e crianças, e que pode e deve ser buscada por aquelas pessoas que visam uma independência financeira, saber como sair de um endividamento, planejar as contas futuras, controlar impulsos consumistas desnecessários em qualquer etapa da vida.

À medida que os conceitos são absorvidos, o jovem, de certa forma, estará mais preparado para lidar com a administração de suas finanças com menos equívocos. Por esta ração, algumas instituições escolares já estão adotando a educação financeira como uma disciplina em seu currículo escolar, com o objetivo de formar jovens mais capacitados e conscientes financeiramente. (OLIVIERI, 2013).

O dinheiro é essencial para que as pessoas possam realizar suas atividades cotidianas, comprar bens materiais, participar de eventos, e lazer pessoais. Para Figueira; Pereira (2014), o "dinheiro é uma ferramenta de status e a autoestima é elevada por meio do consumo". Compreender os complexos movimentos monetários possíveis, após a implementação do plano real, a estabilidade financeira e a redução dos juros é o desafio dos brasileiros.

Em um primeiro momento esta complexidade, foi traduzida apenas em um aumento do mercado consumidor a base do crédito. Essa cultura foi fortalecida pela democratização do crédito que expandiu a oferta de bens e consumo no mercado nacional; não demorou muito para surgir os primeiros efeitos negativos, como endividamentos, inadimplência e desequilíbrio nas financias pessoais. (MOREIRA; CARVALHO, 2013).

Barbosa Filho (2017) destaca, com sua visão ortodoxa, que a crise econômica se instaurou durante o triênio de 2014/2016, e ainda continua presente, ela foi oriunda de um conjunto de choques entre oferta e demanda, em sua maioria ocasionados por políticas públicas que diminuíram a capacidade de crescimento da economia brasileira; neste ponto, cabe destaque para a adoção da Nova Matriz Econômica (NME) por parte do governo brasileiro a partir de 2011/2012.

A NME nasce dos gastos, subsídios e intervenções nos preços por parte do governo federal, na queda artificial dos juros (política monetária) e gastos excessivos (política fiscal), que causou duas consequências atuais; a incapacidade atual de investimento do governo sem criar inflação e o endividamento das famílias em taxas nunca vistos no Brasil.

A expansão e facilidade de se obter créditos possibilitou que o consumo continuasse em alta até 2015, porém os níveis de endividamento das famílias cresceram superiores a massa salarial. A Pesquisa Nacional de Endividamento e inadimplência do consumidor (PEIC) de abril de 2019, realizada pela Confederação Nacional do Comércio de Bens, Serviços e Turismo (CNC) Demonstra que 62,7\% das famílias brasileiras estão endividadas, desse percentual $23,9 \%$ estão com dívidas em atraso e $9,5 \%$ afirmam que não terão condição de quitar as dívidas. (CNC, 2019).

A facilidade de se obter créditos financeiros, aliado a falta de conhecimento e ao difícil acesso de informações financeiras, tem levado muitos consumidores a inadimplência. Dentro do cenário atual, com o crédito chegando a classes menos favorecidas, é de suma importância a implementação de políticas educacionais relacionadas as finanças pessoais que possa auxiliar os cidadãos em um planejamento adequado de seus recursos. (MOREIRA; CARVALHO, 2013).

Um outro fator que pode levar ao endividamento é a compra impulsiva, esse tipo de compra é caracterizado, como um momento que o consumidor se vê obrigado a adquirir um certo produto naquele exato momento, envolve um desejo vivencial para comprar algo e se ocorre com frequência pode levar o indivíduo a ter problemas financeiros. (FIGUEIRA; PEREIRA, 2014).

No entanto, Bruno e Caffe (2018) destacam que a análise das taxas de acumulação de capital e lucro no Brasil, logo após o impacto da crise financeira mundial de 2008, no Brasil, são provenientes da NME, apontam para fatores estruturais da economia brasileira atual, os quais 
não poderiam ser contidos com medidas anticíclicas. Os autores afirmam, "é de pouco efeito a adoção de políticas macroeconômicas contracíclicas".

Ainda a despeito da recessão brasileira, destacam-se outros fatores que contribuíram para o agravamento da crise econômica: a) alteração da política econômica vigente até o ano de 2010 para um modelo em busca da redução dos gastos públicos associado ao lado da oferta; b) adoção de políticas de austeridade; c) eclosão de uma profunda crise política em detrimento das investigações da Operação Lava Jato (BRUNO; CAFFE, 2018).

Desta forma, 2019/20 teve condições macroeconômicas muito diferentes das vividas no Brasil nos últimos 25 anos. Passou-se a ter diminuição da oferta agregada governamental, redução do aumento da dívida pública e das famílias, e uma redução nunca visto nas taxas de juros no Brasil.

Este cenário mudou completamente após a pandemia da COVID-19, depois da declaração de emergência os gastos públicos subiram drasticamente, e concomitantemente houve uma queda na renda das famílias, assim pós, novo Coronavírus, observa-se aumento da dívida dos governos e das famílias no Brasil.

A falta de conhecimento sobre finanças pessoais faz pessoas tomarem decisões que impactam negativamente suas vidas financeiras, ou aumentando os gastos ou reduzindo os ganhos (MOREIRA; CARVALHO, 2013).

Considerando a hipótese que a maioria dos brasileiros não sabem como será o cenário macroeconômico dos próximos 10 anos, este trabalho buscou identificar formas saudáveis de convivência com o dinheiro e o novo cenário macroeconômico. para que as pessoas possam administrar melhor seus créditos e rendimentos.

Assim, analisou-se como cenários macroeconômicos influenciam a vida das pessoas; identificou-se melhores formas de créditos pessoais para os brasileiros; e foi mapeado as melhores formas de identificação de investimentos.

\section{EDUCAÇÃO FINANCEIRA NO BRASIL}

Trabalhar com a relação de valor de produtos e serviços esta no cotidiano de todos. Por esta razão é de fundamental importância saber como utilizar de uma maneira mais correta e saudável financeiramente. Para Cavalcante; Melo; e Almeida (2014) aprender sobre a educação financeira e aplicar esses conhecimentos podem ajudar o individuo ter uma melhor gestão de suas finanças pessoais.

A educação financeira contribui para a construção de uma vida financeiramente saudável e produtiva, cujo maior benefício desse aprendizado é permitir que o indivíduo tenha controle da sua situação financeira.

O departamento de Educação Financeira do Banco central do Brasil (BCB), demonstra "que estamos sujeitos a um mundo financeiro mais complexo que o das gerações anteriores". Por outro lado, os conhecimentos sobre finanças da população não evoluir de acordo com o aumento de complexidade. A ausência de conhecimentos financeiros, aliado a uma maior facilidade de ser obter créditos, tem contribuído para um grande aumento no número de pessoas inadimplentes.

Nos últimos 10 anos foi observado uma grande elevação no número de endividamento da população brasileira. De acordo com dados coletados pelo Serasa Consumidor em 2017, o número de pessoas inadimplentes no Brasil chegou à marca de 61 milhões. Sendo que 31,5\% das dívidas eram relacionadas a bancos e financeiras; 29,1\% empresas de Cartão de Crédito - incluindo Cartões de Loja/Varejo; 19,4\% Telecom; 17,1\% Recuperadoras de crédito e por fim 2,9\% Pequenas e Médias empresas.

Similar problema é encontrado nas famílias, onde não há o hábito de reunir os membros para discutir e elaborar um orçamento familiar. O BCB (2013) constata que "embora todos lidem diariamente com dinheiro, poucos se dedicam a gerir melhor seus recursos. E que $3 \mathrm{em}$ cada 4 famílias sentem dificuldade para chegar ao fim do mês com seus rendimentos".

Por estas razões a Base Nacional comum curricular juntamente com o Ministério da Educação (MEC, 2020) vem colocando a educação financeira entre os temas da atualidade sugeridos para compor o novo currículo escolar, partir da publicação do Decreto no 7.397 , de 22 dezembro de 2010, que instituiu a Estratégia Nacional de Educação Financeira (Enef).

Nos anos de 2011 e 2012, 900 escolas públicas presentes nos estados do Ceará, Minas Gerais, Rio de Janeiro, São Paulo, Tocantins e do Distrito Federal aderiram ao projeto-piloto voltado para avaliar o impacto do uso do material didático produzido, com resultados muito satisfatórios. Já em 2015, chegou a vez das escolas públicas de Joinville (SC) e de Manaus (AM) darem sequência à experiência. Em 2020, 
foi adicionando a matéria Matemática Financeira na BNCC do ensino fundamental (MEC, 2020).

\section{COMO AS PESSOAS PEGAM CRÉDITO}

O crédito é essencial para o financiamento do consumo, seja de pessoas físicas ou jurídicas, o crédito exerce papel fundamental no crescimento econômico e nas flutuações de curto prazo.

De acordo com o BCB (Banco Central do Brasil) as principais maneiras de obtenção de créditos para as pessoas física são por meio de:

- $\quad$ Cheque especial: utilização pelo tomador em situações de curto prazo. Mediante a simples movimentação da conta corrente.

- Crédito pessoal não consignado: corresponde a empréstimos pessoais sem desconto das prestações em folha de pagamento

- Crédito pessoal consignado: corresponde a empréstimos pessoais com desconto das prestações em folha de pagamento.

- Aquisição de veículos:

financiamentos de veículos automotores

- Cartão de crédito: À vista, Rotativo e Parcelado.

- Crédito pessoal vinculado à renegociação de dívidas - empréstimos decorrentes de renegociação ou composição de dívidas vencidas.

- $\quad$ Desconto de cheques - pessoas físicas - operações de crédito para adiantamento de recursos com base em fluxo de caixa vinculado a cheques custodiados.

Toda via, deve-se ter muita cautela Tiryaki et al. (2017), aponta que durante uma expansão da economia, a renda liquida do consumidor aumenta, facilita a obtenção de créditos estimulando uma maior exposição ao risco. Pois com uma boa situação econômica, as instituições financeiras, concederiam mais créditos, elas cedem às pressões competitivas, até mesmo para àqueles consumidores com maior probabilidade de não cumprir com suas dívidas e tornar-se inadimplentes.

Já para Fiori et al. (2017), os dois principais fatores que que acarretam 0 endividamento é o desemprego, devido a atual situação econômica do país, onde muitos funcionários que tinham adquiridos dívidas para serem pagas a longo prazo foram demitidos, ocasionando maiores chances de endividamento. A segunda causa seria o descontrole financeiro, devido a falta de planejamento, pois pessoas gastam valores que estão acima de seus orçamentos na compra de produtos ou serviços, o que ocasiona problemas no momento de realizar os pagamentos.

\section{MELHORES FORMAS DE INVESTIMENTOS RENTÁVEIS}

Na última década, o Brasil veio obtendo redução gradativa nas suas taxas de juros reais, segundo os dados coletados do B.C.B. (Banco central do Brasil) a inflação chegou a marca de $2.5 \%$ em Abril de 2020, seguida por uma taxa Selic de $3.75 \%$ no mesmo período, além de alcançar maior estabilidade econômica.

Em julho de 2020, a taxa Selic esta 2,75\% e a previsão de inflação é de $2,0 \%$, em outras palavras os juros reais saíram de $1,25 \%$ para $0,75 \%$ ao ano, este movimento representa $60 \%$ na queda de juros, este cenário econômico gera a possiblidade das pessoas irem em busca de investimentos mais rentáveis.

O Caderno de Educação Financeira Gestão de Finanças Pessoais do BCB (2018), aponta para a importância de conhecer as três principais características dos investimentos, sendo elas: Liquidez, refere-se á capacidade de um investimento ser transformado em dinheiro; Risco, é a probabilidade de ocorrência de perdas; Rentabilidade, é o retorno, a remuneração do investimento.

Este mesmo caderno, classifica os investidores como; conservador, opta pela segurança correndo o menor risco possível; moderado busca um equilíbrio entre segurança e risco; arrojado visa a rentabilidade sendo capaz de correr grandes riscos. Tendo invista, que quem investe tem como objetivo ganhar dinheiro, ter um perfil de investidor conservador é pouco propício, pois, os conservadores costumam adotar a caderneta de poupança como forma de investimento. Levando em consideração que a poupança rende somente $70 \%$ da taxa Selic quando abaixo de $8,5 \%$ (que hoje está em 2,75\% a.a.) e considerando a atual inflação de $2,0 \%$ seu rendimento real é quase zero.

Ferreira; Gonzales; e Santos (2020) indica que as áreas de investimentos mais rentáveis, são aquelas com maior exposição ao risco, entre as mais utilizadas são: Mercado de ações Ibovespa; Tesouro pré-fixado 2021/2013; Euro mercado; Ouro BM\&F; Mercado do Dólar; Mercado Imobiliário, incluindo shoppings, edifícios, hospitais, casas/apartamentos de aluguéis. Estes investimentos são mercados mais propício para os investidores com um perfil arrojado. 
É importante ressaltar que quanto maior o risco, maior o prêmio, e mais caras as garantias e em alguns casos elas são inexistentes, por outro lado os investimentos conservadores como renda fixa ou poupança existe o FGC (Fundo Garantidor de Crédito) que protege depositantes e investidores no âmbito do Sistema Financeiro Nacional. Dando uma garantia de limite até $\mathrm{R} \$ 250$ mil por cada CPF ou CNPJ, por depósitos e investimentos em cada instituição ou conglomerado financeiro (BACEN, [200-?]).

Desta forma, gerenciar riscos, ter educação financeira e compreender a nova realidade monetária brasileira é a condição sine qua non para termos pessoas com melhor rentabilidade nos seus investimentos e quando participar do mercado de crédito, ter um endividamento coerente, produtivo e que não termine em inadimplência.

\section{PROCEDIMENTOS METODOLÓGICOS}

O trabalho utilizou uma abordagem quantitativa/exploratória para mapear o uso monetário em um cenário de juros baixos e compara-lo ao ocorrido nos últimos 10 anos de políticas macroeconômicas. Esta pesquisa conta com o protocolo 5886/2020 do Sistema Gestor de Pesquisa Unoeste.

Para chegar ao objetivo quantitativo utilizou-se 3 fontes; a primeira, foi o instrumento de coleta de dados análise bibliográfica, "a pesquisa bibliográfica implica em um conjunto ordenado de procedimentos de busca por soluções, atento ao objeto de estudo, e que, por isso, não pode ser aleatório" (LIMA; MIOTO, 2007, p. 38).

Segunda, os dados obtidos de instituições oficiais, entre as mais relevantes cita-se; Banco Central do Brasil (B.C.B.); e Instituto Brasileiros de Geografia e Estatística (IBGE). Terceira fonte foi de importantes instituições financeiras como; Bolsa Brasil Balcão (B3), SERASA, Federação Brasileira de Bancos (FEBRABAN), coletando dados dos últimos 10 anos.

O método exploratório tem como objetivo proporcionar maior familiaridade com o problema, com vistas a torná-ló mais explícito ou a construir hipóteses. O levantamento exploratório e a análise de exemplos e cenários estimulam a compreensão de uma complexa realidade (GIL, 2007).

$\mathrm{Na}$ fase exploratória, analisou-se a possível nova forma de adquirir crédito e fazer investimentos para pessoas físicas, dentro das atuais regras brasileiras e novo cenário macroeconômico que se apresenta.

A etapa mais concreta da investigação, no sentido de obter explicação geral dos fenômenos menos abstratos é o estudo comparativo, para Gil (2012), na medida em que esses métodos esclarecem acerca dos procedimentos técnicos a serem utilizados, proporcionam ao pesquisador os meios adequados para garantir a objetividade e a precisão no estudo de ciências sociais.

A pesquisa comparativa é utilizada na literatura especialmente relacionada às políticas econômicas, esta pesquisa utilizará os dados quantitativos e as informações provenientes da pesquisa exploratória para comparar os níveis de endividamento, o acúmulo de capital e o cenário macroeconômico nos últimos 10 anos.

A análise de dados da pesquisa coutou com o uso da estatística descritiva, segundo Akamine e Yamamoto (2013) "a estatística descritiva é a parte da estatística que trabalha com a organização e apresentação dos dados, por meio de tabelas e gráficos".

Os dados financeiros e econômicos encontrados foram padronizados e consolidados com a ferramenta computacional Microsoft Excel $2019^{\circledR}$ para analisar os dados coletados, e a progressões e previsões utilizou-se o software Gretl que é um software livre que compila e interpreta dados econométricos.

\section{RESULTADOS}

Com a queda dos juros nos últimos 10 anos as pessoas começaram a se endividar, em relação a sua renda, proporcionalmente menos. Toda via isto funciona melhor onde temos melhor índice de educação, Bertoncello, Oliveira e Alexandre (2017), ressaltam que o nível de escolaridade está ligado com o desenvolvimento sócio econômico. Pois uma região que contém maior nível de escolaridade, formam pessoas mais capacitadas e preparas para exercerem suas funções. Obtendo assim, um maior desenvolvimento observado nas regiões sul e sudeste que apontam um melhor desempenho.

Percebe-se que países com um maior nível de escolaridade, tem maior eficiência na gestão de seus recursos, além de atingirem maiores níveis de desenvolvimento econômico, tendo empresas mais rentáveis, trabalhadores com melhores remunerações. Gerando um bemestar maior, com isso conclui-se que a educação de fato contribuiu para uma melhora na renda, tanto para uma pessoa física, empresa ou 
sociedade (BERTONCELLO; OLIVEIRA;

ALEXANDRE, 2017).

Esta hipótese se confirmou nesta pesquisa, com a queda da taxa SELIC nos últimos 10 anos tivemos uma queda da inadimplência em regiões com melhor índice educacional do país a região Sudeste se destacou, mas houve uma relação também na região Sul e Norte, por outro lado, a região Nordeste e Centro Oeste não teve o mesmo desempenho.

Quadro 1. Relação da taxa SELIC e inadimplência por região

Modelo 9: MQO, usando as observações 1-120 $(n=119)$

observações ausentes ou incompletas foram ignoradas: 1

Variável dependente: SELIC

\begin{tabular}{|c|c|c|c|c|c|}
\hline & coeficiente & erro padrão & razão-t & p-valor & \\
\hline const & 0.0966641 & 0.00282234 & 34.25 & $3.57 e-61$ & ***** \\
\hline NegBrasil & 11.2133 & 5.23260 & 2.143 & 0.0343 & *** \\
\hline NegNorte & -1.00889 & 0.573546 & -1.759 & 0.0813 & * \\
\hline NegNordeste & -2.30388 & 1.47791 & -1.559 & 0.1218 & \\
\hline NegCent rooeste & -0.706361 & 0.517363 & -1.365 & 0.1749 & \\
\hline NegSudeste & -5.27712 & 2.21678 & -2.381 & 0.0190 & $* *$ \\
\hline NegSul & -1.62287 & 0.867828 & -1.870 & 0.0641 & $*$ \\
\hline \multirow{2}{*}{\multicolumn{2}{|c|}{$\begin{array}{l}\text { édia var. dependente } \\
\text { oma resíd. quadrados }\end{array}$}} & \multicolumn{2}{|c|}{ D.P. var. dependente } & \multicolumn{2}{|c|}{0.028507} \\
\hline & 0.085855 & \multirow{2}{*}{\multicolumn{2}{|c|}{$\begin{array}{l}\text { E.P. da regressão } \\
\text { R-quadrado ajustado }\end{array}$}} & \multicolumn{2}{|c|}{0.027687} \\
\hline $\begin{array}{l}\text { oma resíd. quadrados } \\
\text {-quadrado }\end{array}$ & 0.104656 & & & \multicolumn{2}{|c|}{0.056691} \\
\hline$(6,112)$ & 2.181931 & \multicolumn{2}{|c|}{ P-valor (F) } & \multirow{2}{*}{\multicolumn{2}{|c|}{0.049864}} \\
\hline og da verossimilhança & 261.5821 & \multicolumn{2}{|c|}{ Critério de Akaike } & & \\
\hline \multicolumn{2}{|c|}{ ritério de Schwarz -489.7103} & \multicolumn{2}{|c|}{ Critério Hannan-Quit } & -501.264 & \\
\hline
\end{tabular}

Fonte: Taxa SELIC no Banco Central negativados SERASA, elaborado pelos autores.

Com a atual taxa Selic de 2,75\% e a crise que o país encontra devido a pandemia causada pelo COVID-19 rentabilidade dos investimentos mais comuns entre os brasileiros está em queda. Devido a baixa rentabilidade da poupança, a queda no valor de algumas ações, aliado a falta de conhecimento de como se comportar nessa situação, grande parte dos investimentos ficaram negativos no primeiro semestre de 2020.

Quadro 2. Investimentos no primeiro semestre de 2020

\begin{tabular}{l|l|l} 
Investimentos & $\mathbf{2 0 2 0}$ & Ganho Real \\
\hline B3 & $-18,56 \%$ & $-18,46$ \\
\hline Dólar & $+23,43 \%$ & $+23,53$ \\
\hline Renda Fixa & $+1,55 \%$ & $+1,65$ \\
\hline Poupança & $+1,16 \%$ & $+1,26$ \\
\hline
\end{tabular}

Fonte: Banco Central, IBGE e B3, elaborado pelos autores.

O endividamento por sua vez em 2020

segue uma relação muito estreita com a o desemprego a renda no país em junho $67,1 \%$ das famílias no Brasil se declararam endividadas e $14,4 \%$ muito endividadas, outro resultado que chama atenção e a proximidade das famílias muito endividadas e o percentual de desemprego no Brasil que em maio esta em $13,6 \%$ e deve chegar em junho com percentuais superiores a $14 \%$. 
Gráfico 1. Percentual de endividamento das famílias brasileiras.

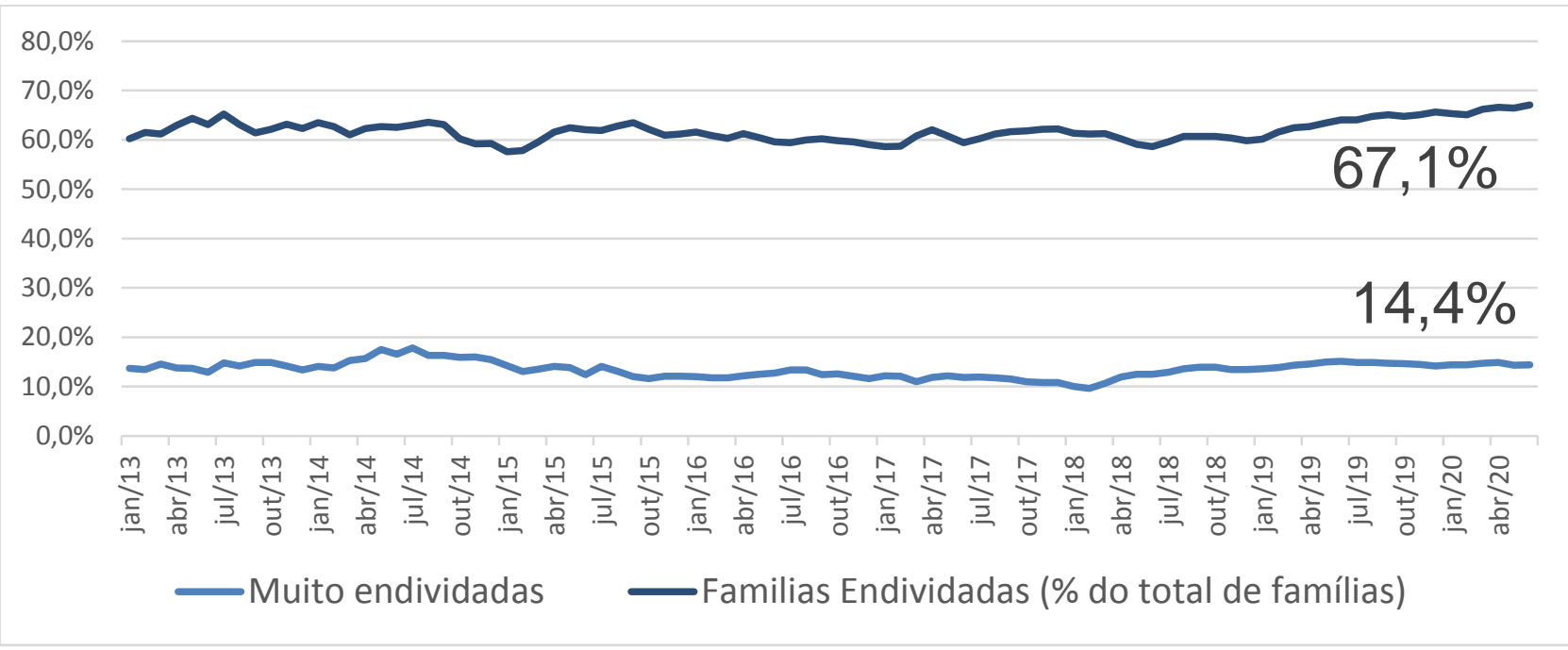

Fonte: IBGE/CNC elaborada pelos autores.

Nota: Site http://www.cnc.org.br/editorias/economia/pesquisas/pesquisa-de-endividamento-e-inadimplencia-doconsumidor-peic-junho-0

Desta forma, é correto afirmar que a atual queda de juros no Brasil não beneficiou a maioria da população, isto porque apesar da queda da taxa SELIC, houve um aumento do endividamento da maioria da população, e ao mesmo tempo, uma queda na rentabilidade dos investimentos.

\section{DISCUSSÕES}

$\mathrm{Na}$ pesquisa foi possível identificar os problemas de endividamento e a taxa base de juros da economia, porém é preciso verificar profundamente a estrutura de mercado do setor bancário no Brasil, apensar de não ser objeto da pesquisa, ter um oligopólio muito concentrado, diminui as possibilidades de escolhas dos tomadores de crédito no mercado, podendo induzir o cliente a aceitar contratos e juros pouco atrativos, mas como não há uma concorrência forte, as opções restritas podem aumentar o endividamento.

Outro fator que deve ser considerado é a baixa educação financeira no Brasil, temos um histórico de altos juros, que proporcionava ganhos fáceis na renda fixa, porém a mudança drástica da base de juros, vai obrigar uma sofisticação nos investimentos e um aperfeiçoamento das ferramentas, este fator deve ser estudado para verificar a tendência dos investidores nos próximos anos.

\section{CONCLUSÃO}

Conclui-se que existe uma correlação entre nível educacional e endividamento das famílias, em um espaço temporal de 10 anos foi possível verificar que a queda da taxa de juros não significa diminuição de endividamento, a redução da taxa SELIC influencia de pesos diferentes, as 5 regiões do Brasil.

Observou-se também a queda dos rendimentos dos investimentos tradicionais e grandes oscilações das rendas variáveis, o dólar demonstrou grandes ganhos e a B3 acumulou enormes perdas em 2020, demonstrando duas necessidades, primeira que é preciso desenvolver mecanismos de defesa em rendas variáveis e que as variações podem ser de ganhos ou perdas muito acima das taxas de juros.

Por fim, recomenda-se maiores estudos relacionando a nova realidade dos baixos juros no Brasil, com a possível rentabilidade de novas aplicações e por fim qual parcela da população vai conseguir desenvolver consciência financeira sofisticada o bastante para lucrar neste novo cenário nacional.

\section{REFERÊNCIAS}

AKAMINE, C. T; YAMAMOTO, R. K. Estudo Dirigido de Estatística Descritiva. 3.ed. São Paulo: Érika, 2013.

BARBOSA FILHO, F. H. A crise econômica de 2014/2017. Estudos Avançados, v. 31, n. 89, p. 51-60, 2017. https://doi.org/10.1590/s0103$\underline{40142017.31890006 .}$ 
BACEN. Banco Central. Nota para a Imprensa de Política Monetária e Operações de Crédito Nova estrutura de dados de crédito - Nota Metodológica, Banco Central do Brasil, [200-?], Disponível em: https://www.bcb.gov.br/ftp/infecon/notaempr.p df. Acesso em 03 maio. 2020.

BCB. Banco Central do Brasil. Caderno de Educação Financeira: gestão de finanças pessoais. Brasília: Banco Central do Brasil, 2013. Disponível

em: https://www.bcb.gov.br/content/cidadaniafinanc eira/documentos_cidadania/Cuidando_do_seu_d inheiro_Gestao_de_Financas_Pessoais/caderno_ cidadania_financeira.pdf. Acesso em: 23 mar. 2020.

BERTONCELLO, A. G.; ALEXANDRE, T.; OLIVEIRA, J. R. S.;. Impacto da Educação Superior para a Mobilidade Social. Revista Colloquium Socialis, Presidente Prudente, v. 1, n. 3. 2017. http://journal.unoeste.br/index.php/cs/article/vi ew/2232/2099. Acesso em: 06 nov.2019. Doi: https://doi.org/10.5747/cs.2017.v01.n3.s016.

BRASIL. Ministério da educação. MEC: apoia inserção da temática educação financeira no currículo da educação básica. Brasília: MEC, 2016. Disponível em: http://portal.mec.gov.br/busca-geral/211noticias/218175739/34351-mec-apoia-insercaoda-tematica-educacao-financeira-no-curriculo-daeducacao-basica. Acesso em: 22 mar. 2020.

BRUNO, M. A. P.; CAFFE A. R. D. Determinantes das Taxas de Lucro e de Acumulação no Brasil: os fatores estruturais da deterioração conjuntural de 2014-2015. Revista de Economia Política, v. 38, n. 2, p. 237-260, 2018 . Disponível em: http://www.rep.org.br/PDF/151-2.PDF. Acesso em: 02 maio.2020. https://doi.org/10.1590/010131572018v38n02a02

CAVALCANTE, B. A. ; MELO, L. M. L. ; ALMEIDA, F. V. H. A importância da educação financeira na tomada de decisões: um estudo com os servidores do centro administrativo e financeiro (caf) do município de quixadá-ce. Revista Expressão Católica, Quixadá v. 3, n 1, 2014. Disponível em: http://publicacoesacademicas.unicatolicaquixada .edu.br/index.php/rec/article/view/1334. Acesso em: 10 mar. $2020 . \quad$ Doi: https://doi.org/10.25190/rec.v3i1.1334.

CNC. CONFEDERAÇÃO NACIONAL DO COMÉRCIO DE BENS, SERVIÇOS E TURISMO. Pesquisa de Endividamento e Inadimplência do Consumidor: abril 2019, 2019. .Disponível em: file:///C:/Users/joaoz/Documents/PEIC\%202019. pdf. Acesso em. 06 nov. 2019.

FERREIRA. A. P.; GONZALES. A.; SANTOS. F. A.; Efeitos de eventual término da isenção do imposto de renda dentro de fundos de investimento imobiliário. Refas, v. 8, n. 3, fev. 2020.

FIGUEIRA, R. F.; PEREIRA, R. C. F. Devo, não nego, pago se puder: uma análise dos antecedentes do endividamento do consumidor. Revista Brasileira de Marketing, v. 13, n. 5. 2014. Disponível em: file:///C:/Users/joaoz/Documents/Artigo\%20fina nceiro\%204.pdf. Acesso em. 06 nov.2019. https://doi.org/10.5585/remark.v13i5.2744.

FIORI, D. D. et al. O efeito da educação financeira sobre a relação entre adimplência. SINERGIA, Rio Grande, v. 21, n. 2, p. 31-45, jul./dez. 2017. Disponível em: file://C:/Users/Dell/Downloads/7215-22804-1PB.pdf. Acesso em: 02 maio. 2020. https://doi.org/10.17648/sinergia-2236-7608v21n2-7215.

GIL, A. C. Como Elaborar Projetos de Pesquisa. 4. ed. São Paulo: Atlas, 2007.

GIL, A. C. Métodos e técnicas de pesquisa social. 6 ed. São Paulo: Atlas, 2012.

LIMA, T. C. S.; MIOTO, R. C. T. Procedimento metodológico na construção do conhecimento científico: A pesquisa bibliográfica. Katálysis, Florianópolis, v. 10, 2007. Disponível em: http://www.scielo.br/scielo.php?script=sci_arttex t\&pid=S141449802007000300004\&lng=en\&nrm= iso\&tlng=pt. Acesso em: 20 out. 2019. Doi: https://doi.org/10.1590/S141449802007000300004 .

MOREIRA, R. C.; CARVALHO, H. L. F. S. As finanças pessoais dos professores da rede municipal de ensino de campo Formoso-BA: um estudo na 
Escola José de Anchieta. Revista de Gestão, Finanças e Contabilidade, Salvador, v. 3, n. 1, 2013. Disponível em: file://C:/Users/joaoz/Documents/Artigo\%20fina nceiro\%202.pdf. Acesso em: 03 nov. 2019. https://doi.org/10.18028/2238-

5320/rgfc.v3n1p122-137.

OLIVIERI, M. F. A. Educação Financeira. ENIAC, Guarulhos, v. 2, n. 1, 2013. Disponível em: https://ojs.eniac.com.br/index.php/EniacPesquis a/article/view/108/pdf_9. Acesso em 03 nov. 2019. https://doi.org/10.22567/rep.v2i1.108.

SERASA EXPERIAN. Serasa Consumidor: Feirão Limpa Nome HISTÓRICO: 7 em cada 10 pessoas que viram sua dívida renegociaram. 2017. Disponível em:

https://www.serasaexperian.com.br/sala-deimprensa/feirao-limpa-nome-historico-7-emcada-10-pessoas-que-viram-sua-dividarenegociaram. Acesso em. 22 mar. 2020.

TIRYAKI, G. F.; GAVAZZA, I. O.; ANDRADE, C. M.; MOTA, A. L. Ciclos de crédito, inadimplência e as flutuações econômicas no Brasil. Revista de Economia Contemporânea, Rio de Janeiro, v.21, n. 1, p. 1-33, 2017. Disponível em: file://C:/Users/Dell/Downloads/artigo\%20de\%20 crédito.pdf. Acesso 03 maio. 2020. Doi: https://doi.org/10.1590/198055272112. 